УДК 332.1

DOI: $10.18101 / 2304-4446-2019-4-22-28$

\title{
ВЗАИМОСВЯЗЬ ПРОЦЕССОВ УРБАНИЗАЦИИ И ОПЕРАЦИОННОГО УПРАВЛЕНИЯ ПРЕДПРИЯТИЕМ (НА ПРИМЕРЕ РЕСПУБЛИКИ БУРЯТИЯ)
}

\section{(C) Булгатова Юлия Сергеевна}

кандидат философских наук, доцент, Бурятский государственный университет имени Д. Банзарова Россия, 670000, г. Улан-Удэ, ул. Ранжурова, 5

E-mail: feu2001@mail.ru

\section{(C) Лосева Анна Юрьевна}

ассистент, Бурятский государственный университет имени Д. Банзарова; аспирант, Байкальский институт природопользования СО РАН Россия, 670000, г. Улан-Удэ, ул. Ранжурова, 5

E-mail: anyta948@yandex.ru

В статье описываются факторы развития процессов урбанизации Республики Бурятия Формирование городских поселений с учетом политических решений об ускоренной урбанизации повлекло множество проблем. Авторами проанализированы статистические данные по демографическим, социальным и экономическим показателям развития Республики Бурятия, которые характеризуют процессы урбанизации. Была выявлена взаимосвязь развития предприятий и уровня урбанизации в Республике Бурятия (данное положение уже ранее рассматривали другие ученые). В заключении предлагается новый путь решения проблем процессов урбанизации через внедрение бизнесинжиниринга. Это позволит рационально управлять процессами урбанизации, считая их аналогами бизнес-процессов. Для формирования благоприятных условий жизнедеятельности населения Республики Бурятия было предложено внедрение на предприятиях операционного управления, что будет способствовать развитию организаций с возможностью активного роста в масштабах производства, сбыта и оказания услуг.

Ключевые слова: социально-экономическое развитие; рынок труда; предприятия; операционное управление предприятием; урбанизация; бизнес-инжиниринг.

\section{Для цитирования}

Булгатова Ю. С., Лосева А. Ю. Взаимосвязь процессов урбанизации и операционного управления предприятием (на примере Республики Бурятия) // Вестник Бурятского государственного университета. Экономика и менеджмент. 2019. № 4. С. 22-28.

Понятие «урбанизация» включает в себя все аспекты процесса образования городов. Так, в работах Бориса Сергеевича Хорева (1932-2003) рассматривается теория расселения населения в СССР, практика создания единой системы расселения в СССР по средствам создания промышленных центров с концентрацией трудовых сил, а также проведен анализ социальных проблем процессов урбанизации, особенно трудовых и демографических [1, с. 193-197].

Со стороны социологических и демографических взглядов урбанизацию рассматривал в своих работах А. Г. Вишневский, он описывает городскую революцию и модернизацию. Необходимо отметить следующее высказывание А. Г. Вишневского: «Урбанизация... несет с собой очень большие перемены, а потому становится одним из источников конфликта внутри общества, особенно 
Ю. С. Булгатова, А. Ю. Лосева. Взаимосвязь процессов урбанизации и операционного управления предприятием (на примере Республики Бурятия)

если протекает стремительно, не оставляя времени на постепенное освоение связанных с нею социальных нововведений» [2, с. 80]. Данное высказывание определяет аспекты противоречивости развития городов СССР и России.

Процессы урбанизации на территории Сибири проходили в короткие сроки в отличие от всей России. Это способствовало появлению городов и городских поселений за счет географической специфики Сибири, а именно транспортной инфраструктуры (крупные железнодорожные пути), а также за счет индустриализации (централизация промышленных производств).

В Республике Бурятия образование городов и городских поселений происходило медленными темпами. Встраивание Бурятии в процессы урбанизации произошло к середине 1970-х гг., отставая на 10 лет от других регионов Сибири [3, c. 476-477]. Именно освоение республики с начала 1970-х гг. (формирование промышленности и строительство Бурятского участка БАМа) позволило к 1990 г. повысить уровень урбанизации до $62,16 \%$ и войти в число урбанизированных регионов.

В последующие годы происходит снижение уровня урбанизации в Республике Бурятия вследствие проведения изменений в структуре городского населения. Намерения сократить количество бедного населения только усилили дифференциацию населения, что повлекло за собой сильное расслоение, рост преступности и заболеваний. Это стало причиной миграции населения в наиболее благоприятные регионы. Тем самым наблюдается общий отток жителей республики с 2000 по 2005 г. на 33814 чел., или на 3,4\% (сокращение не только городского населения, но и сельского). Демографическая нагрузка очень высока в республике: с 2005 г. имеет постоянную тенденцию к росту и в 2018 г. составила 80,7 чел. на 100 трудоспособных (табл. 1).

Таблица 1

Показатели процессов урбанизации в Республике Бурятия 1990-2018 гг. [4]

\begin{tabular}{|l|c|c|c|c|c|c|c|}
\hline \multicolumn{1}{|c|}{ Год } & $\mathbf{1 9 9 5}$ & $\mathbf{2 0 0 0}$ & $\mathbf{2 0 0 5}$ & $\mathbf{2 0 1 0}$ & $\mathbf{2 0 1 5}$ & $\mathbf{2 0 1 6}$ & $\mathbf{2 0 1 7}$ \\
\hline Уровень урбанизации, \% & 59,63 & 59,73 & 57,4 & 57,8 & 58,9 & 59 & 58,9 \\
\hline $\begin{array}{l}\text { Общая демографическая } \\
\text { нагрузка, чел. на 100 тру- } \\
\text { доспособных }\end{array}$ & 76,54 & 67,04 & 56,54 & 59,33 & 72,45 & 75,54 & 78,32 \\
\hline $\begin{array}{l}\text { Численность населения, } \\
\text { чел. }\end{array}$ & $\begin{array}{c}1037 \\
366\end{array}$ & $\begin{array}{c}1004 \\
808\end{array}$ & $\begin{array}{c}970 \\
994\end{array}$ & $\begin{array}{c}969 \\
736\end{array}$ & 978495 & 982284 & 984134 \\
\hline Процент бедных, \% & 54,3 & 53,5 & 32,6 & 19,2 & 17,7 & 18,2 & 18,5 \\
\hline $\begin{array}{l}\text { Реальные доходы населе- } \\
\text { ния, \% к прошлому году }\end{array}$ & $-17,3$ & 2,5 & 11,6 & 2,5 & 0,2 & $-6,6$ & $-3,1$ \\
\hline $\begin{array}{l}\text { Трудовая миграция между } \\
\text { регионами: \% работающих } \\
\text { в других регионах }\end{array}$ & - & 0,23 & 0,92 & 0,86 & 1,68 & 1,74 & 2,29 \\
\hline $\begin{array}{l}\text { ВРП на душу населения, } \\
\text { руб. }\end{array}$ & $\begin{array}{c}7422 \\
000\end{array}$ & $\begin{array}{c}21 \\
\text { Ч55 }\end{array}$ & $\begin{array}{c}77 \\
533\end{array}$ & $\begin{array}{c}198 \\
570\end{array}$ & $\begin{array}{c}206 \\
880,3\end{array}$ & $\begin{array}{c}202 \\
627,8\end{array}$ & 202 \\
\hline $\begin{array}{l}\text { Число предприятий и ор- } \\
\text { ганизаций, ед. }\end{array}$ & $\begin{array}{c}13 \\
973\end{array}$ & 504 & $\begin{array}{c}14 \\
829\end{array}$ & $\begin{array}{c}19 \\
011\end{array}$ & $\begin{array}{c}20 \\
309\end{array}$ & $\begin{array}{c}20 \\
933\end{array}$ & 20 \\
\hline
\end{tabular}


На 2017 г. уровень урбанизации составил 58,9\%, что на 0,1 п.п. меньше, чем в прошлом году, и на 0,73 п.п. меньше, чем в 1995 г.

В соответствии с собранными статистическими данными, представленными в таблице 1, был выявлен факт зависимости процессов урбанизации от числа предприятий в Республике Бурятия (рис. 1 и 2).

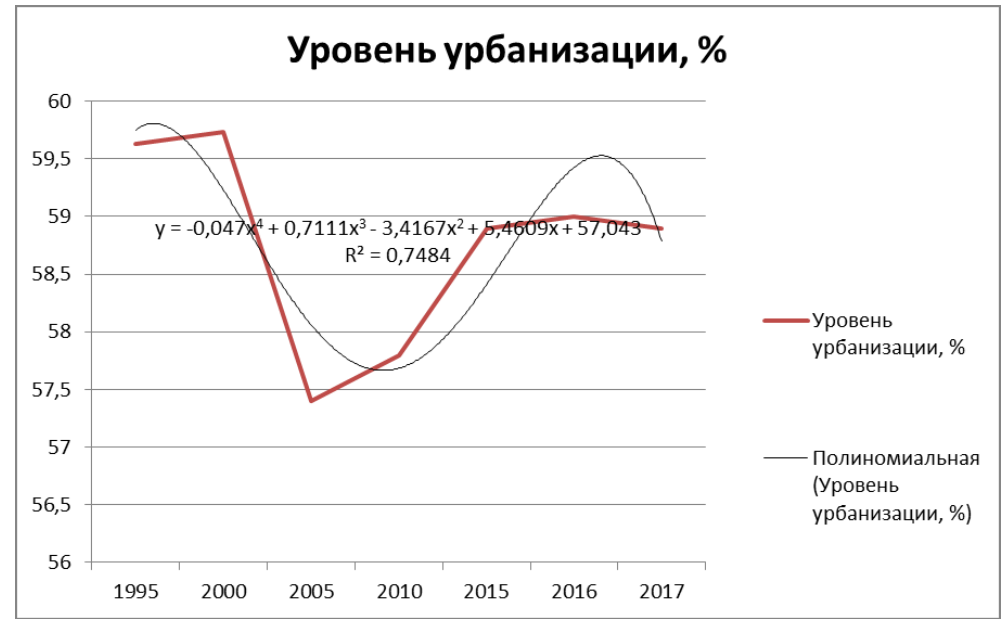

Рис. 1. Уровень урбанизации в Республике Бурятия за 1995-2017 гг.

В 2005 г. наблюдалось существенное снижение числа предприятий в Республике Бурятия, что способствовало перераспределению трудовой силы: трудовая миграция в другие регионы составила 0,93\%. Конечно же, это не единственный фактор снижения уровня урбанизации в период 2000-2005 гг. Перечислим еще два фактора, которые, на наш взгляд, имели большое влияние:

1) в 1998 г. произошел дефолт;

2) «шоковая терапия» 1990-х гг. повлекла сокращение объемов инвестиций, что привело к спаду объемов производства и капитального строительства.

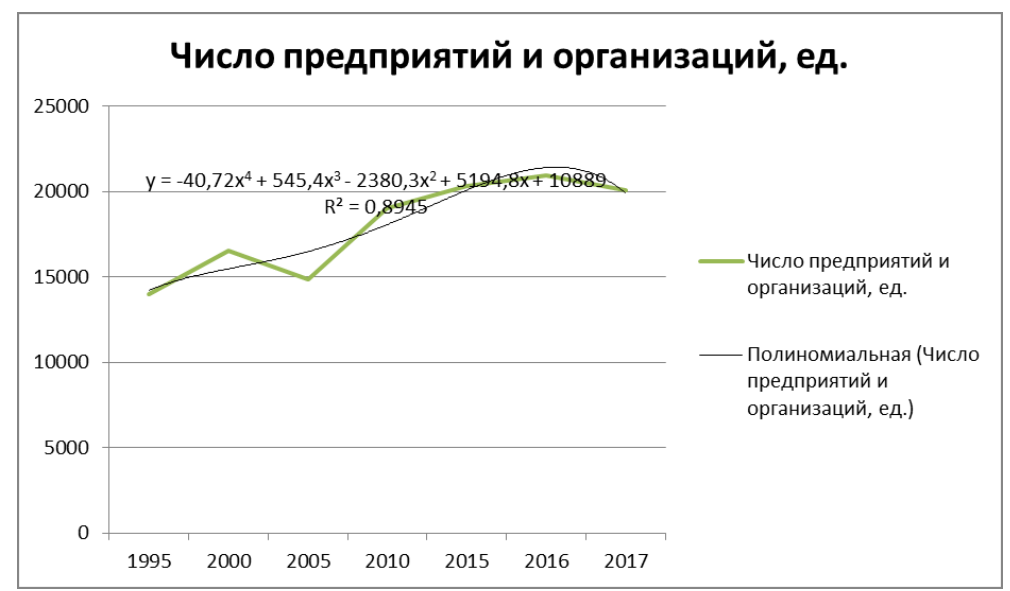

Рис. 2. Число предприятий и организаций в Республике Бурятия за 1995-2017 гг. 
Ю. С. Булгатова, А. Ю. Лосева. Взаимосвязь процессов урбанизации и операционного управления предприятием (на примере Республики Бурятия)

После спада производства в 2000-2005 гг. правительство Республики Бурятия делает перспективные попытки создать условия для оживления экономики: содействие инвестиционной активности за счет республиканских и частных инвестиций, организация крупных объединенных предприятий (самый первый холдинг ГУП «Локомотивовагоноремонтный завод», «Вертолеты Ми» и др.). Но наступление мирового кризиса 2008 г. не позволило повысить активность предприятий в Республике Бурятия до значений периода 1995-2000 гг.

Плановое развитие процессов урбанизации Республики Бурятия в советское время, которое предполагало навязывание централизации городов с учетом централизации промышленности, создает большие проблемы, особенно в области нагрузки на инфраструктуру города. Дальнейшее стихийное развитие процессов урбанизации только усугубило положение и затормозило развитие городов в Республике Бурятия. Таким образом, процессами урбанизации необходимо постоянно управлять.

С точки зрения управляемого процесса имеется возможность выделения определенных процессов, похожих на бизнес-процессы предприятия, а именно создание определенных сфер деятельности внутри города/городского поселения, для инфраструктуры (для города - это транспортная, социальная, экономическая, для предприятия - оборудование, здания). Поэтому считаем возможным и эффективным внедрение бизнес-инженирнга в управление процессами урбанизации, который подразумевает выполнение комплекса проектировочных работ по разработке методов и процедур управления городом (бизнесом), когда без изменения принятой структуры управления городом/городским развитием (в организации) достигается улучшение ее экономического, социального и демографического положения [5, с. 96-118]. Другими словами, необходимо, не изменяя формы управления (как прописано в законодательстве), проектировать пути эффективного протекания процессов урбанизации, а также назначать ответственного по каждому направлению. Следующим направлением улучшения существующей ситуации по развитию городов, на наш взгляд, является рассмотрение способа повышения эффективной деятельности предприятий.

В настоящее время все больше работ посвящено определению операционной эффективности предприятий. Общее определение данного понятия состоит во взаимоотношении затраченных ресурсов и полученных результатов. При этом данная взаимосвязь должна носить не только положительный эффект, но и показывать достаточно высокие темпы роста результатов по сравнению с затраченными ресурсами [6].

Операционная эффективность предприятия подразумевает не просто конечный результат, а именно процесс достижения лучшего. Многие воспринимают данную эффективность как стратегию развития предприятия. Главное ее отличие состоит в форме предоставления планов по работе: стратегия определяет высшие цели, основные пути достижения целей, представлены основные показатели деятельности, а операционная эффективность - тактические пути развития с использованием всех мелких (возможно незначимых для высших целей) факторов. Операционная эффективность предприятия всегда предполагает усовершенствование бизнеспроцессов в короткие сроки с учетом быстрой реакции на изменения рынка. Данное обстоятельство всегда позволит малому бизнесу сосредоточиться на выявле- 
нии проблем внутри организации и повысить конкурентоспособность по сравнению с крупными организациями, которые направлены на достижение стратегических целей, разработанных на длительный период.

Именно для малого бизнеса, который в настоящее время набирает обороты в своем развитии и позволяет развиваться экономике России, операционная эффективность позволит конкурировать с крупными организациями и создавать благоприятные условия для возможности вовлечения малого бизнеса в «большую игру» на рынке [7, с. 3376-3378].

Также необходимо рассмотреть пользу от внедрения операционной эффективности в область трудовых ресурсов: повышение конкурентоспособности позволит увеличивать производство, сбытовой рынок и т. п., что в итоге создаст потребность в трудовых кадрах с хорошей оплатой за эффективную работу.

Для внедрения операционной эффективности на предприятия необходимо рассмотреть ее принципы:

1. Совершенствование бизнес-процессов (формирование оптимальной логической последовательности выполнения работ, услуги, производство продукции/товара).

2. Рациональное использование кадров (определение оптимальных главных функций и ответственных по каждой из этих функции, при этом необходимо соблюдать допустимую нагрузку на отдельного сотрудника организации; составление оптимальной схемы взаимодействия сотрудников организации без заминок и «сломанного телефона»).

3. Экономия ресурсов без потери качества (создание условий для снижения процента брака на производстве, составление рационального использования ресурсов, внедрение безотходного производства).

4. Мониторинг изменений внутри и снаружи (своевременное выявление изменений условий и факторов, а также оперативная адаптация к изменениям).

5. Эффективная система контроля и учета (создание условий равномерного распределения между функциями заполнения отчетности и непосредственного выполнения обязанностей сотрудниками, т. е. определить наиболее важные формы отчетности и не перегружать их мелкими пунктами, освободившееся время у ответственных направить на выполнение важных функций).

Внедрение операционной эффективности на предприятие возможно с использованием нескольких способов, однако, на наш взгляд, наиболее рациональным является система сбалансированных показателей. Данная система уже апробирована на предприятиях разных форм, что является хорошим показателем для внедрения.

Система сбалансированных показателей определяет важнейшие показатели и нормативы по ним, а также позволяет усовершенствовать бизнес-процессы на их основе. Для каждого предприятия система показателей выбирается индивидуально в зависимости от сферы деятельности, объемов производства.

Таким образом, внедрение операционной эффективности на предприятия Республики Бурятия позволит:

1) увеличивать денежные потоки внутри региона;

2) создавать рабочие места с адекватной оплатой труда;

3) насыщать местный бюджет; 
Ю. С. Булгатова, А. Ю. Лосева. Взаимосвязь процессов урбанизации и операционного управления предприятием (на примере Республики Бурятия)

4) создавать благоприятные условия для жизнедеятельности населения (формирование обеспечивающей инфраструктуры, повышение доходов населения, формирование населенных пунктов городского типа — городов).

\section{Литература}

1. Лосева А. Ю. Парадигмы и методологии изучения урбанизации // Социальноэкономическое развитие России и Монголии: проблемы и перспективы: материалы VI Междунар. науч.-практ. конф. Улан-Удэ, 2019. С. 193-197.

2. Вишневский А. Г. Серп и рубль. Консервативная модернизация в СССР. Москва: ОГИ, 1998. С. 80.

3. Кузнецова Я. А. Особенности урбанизации и формирования городского населения в Сибири (на примере Республики Бурятия) // Иркутский историко-экономический ежегодник: 2012 / Байкальский государственный университет. Иркутск, 2012. С. 473-478.

4. Официальный сайт Территориального органа Федеральной службы государственной статистики по Республике Бурятия [Электронный ресурс]. URL: https://burstat.gks.ru/ (дата обращения: 12.06.2019).

5. Аржитова Ю. С. Информационные технологии в управлении деятельностью социальных систем в условиях трансформации российского общества: дис. ... канд. филос. наук: 09.00.11. Улан-Удэ, 2009. С. 96-118.

6. Новакова О. Н. Проблемы повышения эффективности операционной деятельности предприятия [Электронный ресурс] // Символ науки. 2016. № 9-1. URL: https://cyberleninka.ru/article/n/problemy-povysheniya-effektivnosti-operatsionnoydeyatelnosti-predpriyatiya (дата обращения: 12.06.2019).

7. Гараева Д. Р. Операционная эффективность как фактор повышения конкурентоспособности банка // Концепт. 2017. Т. 39. С. 3376-3380.

\section{CORRELATION BETWEEN URBANIZATION PROCESSES AND OPERATIONAL MANAGEMENT OF AN ENTERPRISE (CASE STUDY OF THE REPUBLIC OF BURYATIA)}

Yulia S. Bulgatova

Cand. Sci. (Philos.), A/Prof.,

Dorzhi Banzarov Buryat State University

5 Ranzhurova St., Ulan-Ude 670000, Russia

E-mail: feu2001@mail.ru

Anna Yu. Loseva

Assistant,

Dorzhi Banzarov Buryat State University

Research Assistant,

Baikal Institute of Nature Management SB RAS

5 Ranzhurova St., Ulan-Ude 670000, Russia

E-mail: anyta948@yandex.ru

The article describes the factors of urbanization processes development in the Republic of Buryatia. Creation of urban settlements with account of political decisions on accelerated urbanization entailed many problems. We have analyzed the statistics on demographic, social and economic performance of the Republic of Buryatia, which characterizes the processes of urbanization; revealed the correlation between the development of enterprises and the level of urbanization in the Republic of Buryatia (other scientists have already consid- 
ered this provision). In conclusion the article proposes to solve the problems of urbanization processes through the introduction of business engineering. This would enable managing urbanization processes as analogues of business processes. To create favorable living conditions for the population of the Republic of Buryatia, we have proposed an introduction of operational management at enterprises, which will contribute to active growth of production, sales and provision of services.

Keywords: socio-economic development; labor market; enterprises; operational management of an enterprise; urbanization; business engineering. 